\title{
Early propranolol treatment ameliorates endothelial dysfunction in experimental septic lung
}

\author{
Ezgi Özyılmaz ${ }^{1, A-F}$, Hacer Sinem Göktürk Büyüknacar²,A,B,E,F, Emine Kllı̧ Bağır, 3,B,E,F, Leman Sencar ${ }^{4, B, E, F}$, \\ Özlem Görüroğlu Öztürk ${ }^{5, B, E, F}$, Ismail Cem Eray ${ }^{6, B, E, F}$, Yusuf Kenan Dağlıoğlu, ${ }^{7, B, E, F}$, Oya Baydar ${ }^{1, D-F}$, \\ Gülşah Seydaoğllu ${ }^{8, A, C, E, F}$, Ufuk Özgü Mete ${ }^{4, B, E, F}$, Derya Gümürdülü̈3,B,E,F , Ali Kocabaş ${ }^{1, A, E, F}$ \\ ${ }^{1}$ Department of Chest Diseases, Faculty of Medicine, Çukurova University, Balcall, Turkey \\ 2 Department of Pharmacology, Faculty of Pharmacy, Çukurova University, Balcalı, Turkey \\ ${ }^{3}$ Department of Pathology, Faculty of Medicine, Çukurova University, Balcalı, Turkey \\ ${ }^{4}$ Department of Histology and Embryology, Faculty of Medicine, Çukurova University, Balcalı, Turkey \\ ${ }^{5}$ Department of Biochemistry, Faculty of Medicine, Çukurova University, Balcalı, Turkey \\ ${ }^{6}$ Department of General Surgery, Faculty of Medicine, Çukurova University, Balcalı, Turkey \\ ${ }^{7}$ Department of Microbiology, Faculty of Medicine, Çukurova University, Balcalı, Turkey \\ ${ }^{8}$ Department of Biostatistics, Faculty of Medicine, Çukurova University, Balcalı, Turkey \\ A - research concept and design; $\mathrm{B}$ - collection and/or assembly of data; $\mathrm{C}$ - data analysis and interpretation; \\ $D$ - writing the article; $E$ - critical revision of the article; $F$ - final approval of the article
}

Address for correspondence

Ezgi Özyllmaz

E-mail: ezgiozyilmaz@hotmail.com

Funding sources

This study was funded by the Scientific Research

Project Unit of Çukurova University, Balcalı, Turkey.

Conflict of interest

None declared

Received on July 7,2017

Reviewed on July 31, 2017

Accepted on October 4, 2017

Published online on July 3, 2018

Cite as

Özyllmaz E, Büyüknacar HSG, Bağır EK, et al. Early propranolol treatment ameliorates endothelial dysfunction in experimental septic lung. Adv Clin Exp Med. 2019;28(3):291-297. doi:10.17219/acem/78248

DOI

10.17219/acem/78248

Copyright

Copyright by Author(s)

This is an article distributed under the terms of the

Creative Commons Attribution Non-Commercial License

(http://creativecommons.org/licenses/by-nc-nd/4.0/)

\section{Abstract}

Background. Recent reports have indicated an improved prognosis in sepsis with $\beta$-blocker agents; however, the underlying action mechanism is still under debate.

Objectives. The aim of this study was to investigate the potential effect of propranolol on endothelial dysfunction in septic rats.

Material and methods. The cecal ligation and puncture model (CLP) was used to generate sepsis. Adult male Wistar-Albino rats were divided into 4 groups: group 1 was a sham group, group 2 received sterile saline, group 3 received $10 \mathrm{mg} / \mathrm{kg}$ of propranolol 3 days before the intervention, and group 4 received $10 \mathrm{mg} / \mathrm{kg}$ of propranolol $30 \mathrm{~min}$ after CLP. Six rats from each group were sacrificed $24 \mathrm{~h}$ postoperatively. The remaining rats were followed for survival. We have also evaluated the effects on systemic inflammation, coagulation and the lung tissue with immunohistochemical and electron microscopic evaluation.

Results. Serum tumor necrosis factor alpha (TNF-a) and plasminogen activator inhibitor-1 (PAl-1) levels, as well as tissue TNF-a scores were elevated in septic rats. Electron microscopic examination of the lung tissue showed endothelial dysfunction in the sepsis group. Pretreatment significantly improved survival. Moreover, pre-treatment altered serum vascular endothelial growth factor receptor-1 (VEGFR-1) levels and post-treatment reduced serum PAI-1 and VEGFR-1 levels. In both the pre- and post-treatment groups, electron microscopic examination revealed improvement of the destroyed lung endothelium and showed only mild alterations in the cytoplasmic organelles, especially in the mitochondria of the endothelial cells.

Conclusions. These results suggest that the improved outcome with $\beta$-blockers in sepsis may be due to the ameliorated endothelial dysfunction. Further studies focusing on the potential effect of $\beta$-blockers on the endothelium may lead to a better understanding of sepsis.

Key words: sepsis, endothelial dysfunction, experimental, $\beta$-blockers 


\section{Introduction}

Sepsis is a leading cause of mortality and morbidity. ${ }^{1} \mathrm{Al}-$ though its precise pathogenetic mechanisms are not fully understood, it is now clear that endothelial activation and dysfunction lead to persistent microvascular dysfunction and related multi-organ failure. ${ }^{2}$ However, the underlying mechanism of endothelial dysfunction in sepsis is still unknown.

The adrenergic system is not only a key modulator of organ function and cardiovascular homeostasis, but also a powerful regulator of the immune system. Both the lymphoid organs and the vast majority of lymphoid cells express $\beta$-adrenergic receptors on their surfaces. ${ }^{3}$ Sympathetic activation is a well-known feature of sepsis, essential for cardiovascular and metabolic compensation. In addition, sympathetic activation may mediate immune modulation in sepsis. ${ }^{4}$ Adrenergic activation induces monocyte production and monocyte-mature macrophage differentiation in bone marrow via $\beta 2$ receptors that are functionally different in cytokine response. ${ }^{5,6}$ Although plasma catecholamine levels are increased during inflammation and sepsis, it has been shown that persistent elevations due to excessive stimulation lead to $\beta$-adrenoceptor downregulation and immune suppression through the modulation of cell-mediated immunity. ${ }^{7,8}$ In a clinical study, Boomer et al. showed clear immune suppression in patients who died following sepsis. ${ }^{9}$ Today, $\beta$-blockers are one of the mainstay of treatments of coronary artery disease and chronic heart failure. Also, recent studies have demonstrated that $\beta$-blockers might have a novel therapeutic potential against several hypermetabolic states, such as sepsis or burn injury, by attenuating catecholamineinduced metabolic alterations and excessive inflammatory responses. ${ }^{10}$ However, the underlying mechanism of action is still under debate.

The aim of this study was to investigate the potential effect of propranolol, a non-selective $\beta$-blocker, on endothelial dysfunction in septic rats. Toward the realization of this goal, we treated rats with propranolol before and after lethal sepsis. We evaluated the effects of this treatment strategy on systemic inflammation, coagulation and the lung tissue with immunohistochemical and electron microscopic evaluation, and on survival.

\section{Material and methods}

The study protocol was approved by the animal research ethical committee of the institute and all experiments were performed according to the rules of the Guide for the Care and Use of Laboratory Animals (National Institutes of Health publication No. 85-23, revised 1996).

\section{Drugs and the experimental model}

The propranolol was obtained from Sigma Laboratories (P-0884) (Sigma-Aldrich, St. Louis, USA). Experimental sepsis was induced with cecal ligation and puncture (CLP). After $80 \mathrm{mg} / \mathrm{kg}$ of ketamine $+5 \mathrm{mg} / \mathrm{kg}$ of xylazine anesthesia, a midline laparotomy was performed, and the cecum was ligated at the $75 \%$ proximal part of the ileocecal valve and thoroughly perforated with an 18-gauge needle. The cecum was then relocated into the abdominal cavity, and the peritoneum, fasciae and abdominal muscles were closed by simple interrupted sutures. ${ }^{11}$

\section{Animals and the experimental schedule}

Forty-two adult male Wistar-Albino rats weighing $300 \pm 25$ g were procured from the experimental animal laboratory of our institute. They were maintained on a standard diet and given water ad libitum under appropriate conditions. The animals were randomly divided into 4 groups as follows: group 1 was the sham group $(n=6)$, in which laparotomy was performed without the induction of sepsis with CLP; group 2 was the septic control group $(n=12)$, which was twice injected intraperitoneally (i.p.) sterile saline (the same volume as propranolol) for 3 consequtive days before CLP; group 3 was the prepropranolol group $(n=12)$, which was given an i.p. dose of $10 \mathrm{mg} / \mathrm{kg}$ of propranolol for 3 consecutive days before CLP; and group 4 was the post-propranolol group $(n=12)$, which was administered i.p. a dose of $10 \mathrm{mg} / \mathrm{kg}$ of propranolol $30 \mathrm{~min}$ following CLP. The abovementioned doses of either propranolol or saline were selected according to a previous study and were administered every $12 \mathrm{~h}$ for both the pre-and post-propranolol groups. ${ }^{12}$ Cecal ligation and puncture was performed in all groups as previously described, except group 1 (sham), and on the $3^{\text {rd }}$ day of the experiment and $1 \mathrm{~h}$ after the last injection, all animals were given i.p. $2 \mathrm{ml} / 100 \mathrm{~g}$ of pre-warmed $\left(37^{\circ} \mathrm{C}\right)$ sterile saline. After CLP, survival analysis was initiated and the animals were observed each hour over the subsequent $120 \mathrm{~h}$ for mortality, and the survival time was recorded. On the $4^{\text {th }}$ day, $24 \mathrm{~h}$ after the last CLP, 6 animals from each group were re-anesthetized and blood samples were obtained; the animals were sacrificed with cardiac puncture, and the lung tissue was immediately excised and divided in half for immunohistochemical analysis and electron microscopic evaluation. The samples were kept at $-80^{\circ} \mathrm{C}$ under appropriate conditions until analyzed. The remaining animals underwent survival follow-up.

\section{Biochemical assay}

The plasma levels of rat tumor necrosis factor alpha (TNF- $\alpha$ ) (Ref. No. BMS622; e-Bioscience, Vienna, Austria), plasminogen activator inhibitor-1 (PAI-1) (Ref. No. DZE201110637; Sunred, Shanghai, China), vascular 
endothelial growth factor (VEGF) (Ref. No. DZE201110660; Sunred), and VEGF receptor-1 (VEGFR-1) (Ref. No. E20150604052; Hangzhou, China) were measured with standard sandwich enzyme-linked immunosorbent assay (ELISA) methods, and the results were presented in $\mathrm{pg} / \mathrm{mL}$ for TNF- $\alpha$, AU/mL for PAI-1, ng/L for VEGF, and $\mathrm{ng} / \mathrm{mL}$ for VEGFR-1.

\section{Light microscopy and immunohistochemical examination}

In order to investigate lung tissue inflammation due to sepsis, immunohistochemical staining was performed on $5 \mu \mathrm{m}$ sections of formalin-fixed, paraffin-embedded tissue, using antibody to TNF- $\alpha$ (ab6671; Abcam, Cambridge, UK) and interleukin (IL)-6) (ab6672; Abcam, Cambridge, UK). The visualization system used was BenchMark XT with heat-induced epitope retrieval (CC1 solution; Ventana Medical Systems, Inc., Tucson, USA) and the iView DAB detection kit (Ventana). Slides stained with anti-TNF- $\alpha$ and anti-IL- 6 were examined in 5 high-power microscopic fields ( $\times 400$ magnification; Nikon-ECLIPSE 80I; Nikon, Tokyo, Japan). Immunohistochemical evaluation was performed by the histological score (HSCORE) system. The HSCORE was calculated using the following equation: HSCORE = _Pi $(i+1)$, where $\mathrm{i}$ is the intensity of labeling with a value of 1,2 or 3 , and $\mathrm{Pi}$ is the percentage of the labeled cells, varying from 0 to $100 \%$.

\section{Electron microscopy}

For electron microscopic examination, the lung tissue samples were fixed in 5\% glutaraldehyde solution for $4 \mathrm{~h}$. The tissue samples were then washed twice in Millonig phosphate buffer for $10 \mathrm{~min}$, then postfixed in $1 \%$ osmium tetraoxide $\left(\mathrm{OsO}_{4}\right)$ for $2 \mathrm{~h}$ and washed in a buffer solution for $10 \mathrm{~min}$ to remove the $\mathrm{OsO}_{4}$. Then, the tissue samples were dehydrated in graded ethanols. For clearing, the tissue samples were put in propylene oxide, embedded in araldite and polymerized at $64^{\circ} \mathrm{C}$ for $48 \mathrm{~h}$. Tissue sections $50 \mathrm{~nm}$ in thickness were obtained using Reichert Ultracut-S ultramicrotome (Leica, Wetzlar, Germany), and the sections were stained with uranyl acetate and lead citrate. After staining, they were examined with a JeolJEM 1400 transmission electron microscope (Jeol, Ltd., Tokyo, Japan).

\section{Statistical analysis}

For each continuous variable, normality was checked by the Kolmogorov-Smirnov and Shapiro-Wilk tests, and by histograms. The comparisons between groups were conducted using Student's t-test or the analysis of variance (ANOVA) for normally distributed data, and the MannWhitney U test and Kruskal-Wallis test were used for the data not normally distributed. Bonferroni correction was applied for multiple comparisons. The rates of mean or median survival were estimated with the use of the KaplanMeier method and the curves were compared with the use of the log-rank test. Data was expressed as mean \pm standard deviation (SD) and as median (min-max); p-value $<0.05$ was considered statistically significant. All reported p-values are 2-tailed. Statistical analysis was performed using the statistical package SPSS v. 20.0 (IBM Corp., Armonk, USA).

\section{Results}

\section{Pre-propranolol treatment improved the overall survival in septic rats}

Pretreatment of septic rats with propranolol significantly increased survival hours $(120 \mathrm{~h})$ compared to the septic control group (mean: $28 \mathrm{~h}$; median: $14 \mathrm{~h}$ ) and post-propranolol group (mean: 38.9 h; median: 29.5 h) (log-rank test; $\mathrm{p}=0.003$ ) (Fig. 1). The mortality rate reached $83.7 \%$ at the $17^{\text {th }} \mathrm{h}$ in the septic controls ( 5 dead) and it reached the same rate $(83.7 \%)$ later (at the $62^{\text {nd }} \mathrm{h}$ ) in the post-propranolol group ( 6 dead). The mortality rate was prominently lower $\left(16.3 \%\right.$ at the $\left.120^{\text {th }} \mathrm{h}\right)$ in the rats which received propranolol before the induction of sepsis (only 1 dead). None of the animals in the sham group died.

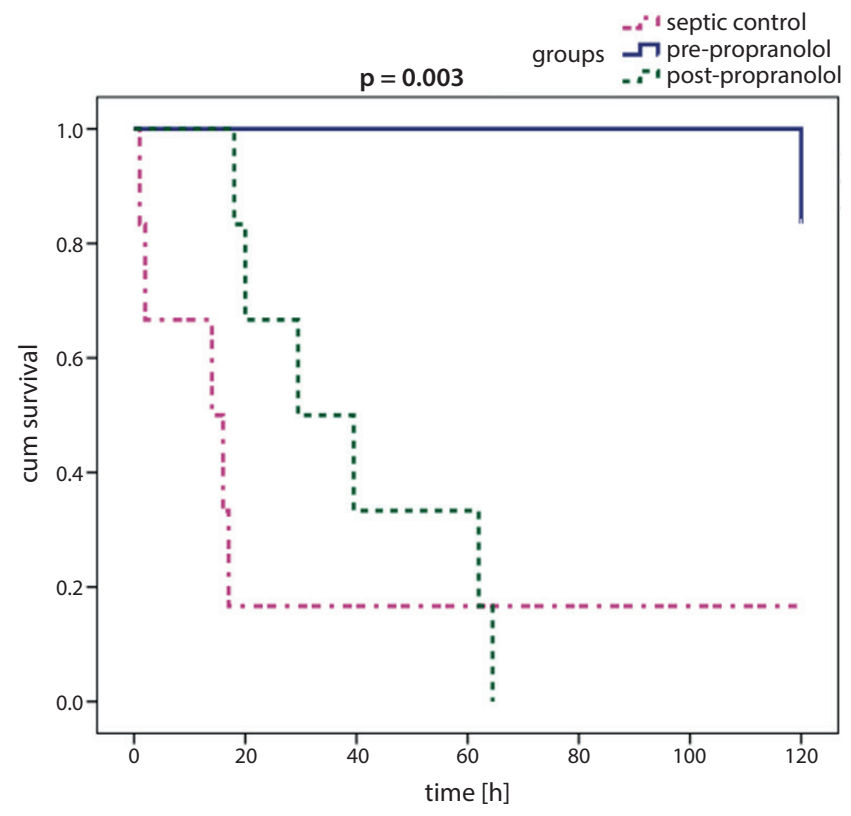

Fig. 1. Cumulative survival curves according to study groups

Pre-treatment of septic rats with propranolol significantly increased survival hours (120 h) compared to the septic control and post-propranolol groups. 


\section{Propranolol improved serum inflammatory and endothelial markers}

Serum TNF- $\alpha$ and PAI-1 levels were elevated in septic rats in comparison to the sham group $(p=0.036$ and $\mathrm{p}=0.006$, respectively). Pre- or post-propranolol treatment failed to decrease serum TNF- $\alpha$ levels; pretreatment altered serum VEGFR-1 levels $(\mathrm{p}=0.037)$ and post-treatment reduced serum PAI-1 levels $(\mathrm{p}=0.013)$ and serum VEGFR-1 levels $(\mathrm{p}=0.016)($ Table 1$)$.

\section{Light microscopy and immunohistochemical evaluation}

The TNF- $\alpha$ score of the lung tissue was significantly higher in septic rats compared to the sham group $(\mathrm{p}<0.05)$. Both pre- and post-propranolol treatment failed to improve lung immunohistochemical results (Table 2, Fig. 2).

\section{Electron microscopy}

Electron microscopic examination of the lung tissue of the sham group revealed a normal histological appearance in which the nucleus, cytoplasmic organelles and the underlying basal lamina of the capillary endothelial cells preserved their structure. In contrast, the septic control group showed an increased amount of heterochromatin in the nuclei of the capillary endothelial cells, which were located in the interalveolar septum. Furthermore, there was increased vacuolization in the cytoplasm of the endothelial cells. This group also displayed enlarged mitochondria and distractions in the crista of the mitochondria. There were surfactant-like structures and phagocytic bodies in the cytoplasm of the macrophages. It is noteworthy that the amounts of collagen fibers were increased, along with the interalveolar septum. Moreover, it was observed that the interalveolar septum became thickened in this group.

In the pre-propranolol treatment group, it was observed that the capillary endothelial cells preserved their fine structures in many areas. However, it was seen in some areas that the amount of heterochromatin increased in the nuclei of the endothelial cells and there were mild alterations in the mitochondria. The macrophages were noticeably higher in number in the interstitium and they had phagocyte surfactant-like structures.

In the post-propranolol treatment group, electron microscopic examinations showed that the capillary endothelial cells and the underlying basal lamina preserved their normal structures in many areas, as in the pre-propranolol group. However, in some areas there were mild alterations in the cytoplasmic organelles, especially in the mitochondria of the endothelial cells. Enlarged mitochondria and fragmentation were found in the crista of the mitochondria (Fig. 3).

\section{Discussion}

The present study showed that systemic administration of the non-selective $\beta$-adrenergic blocker propranolol

Table 1. The distribution of the TNF-a, PAI-1, VEGF, and VEGFR-1 levels between the groups

\begin{tabular}{|c|c|c|c|c|c|}
\hline Biomarker & $\begin{array}{l}\text { Group } 1 \\
\text { sham }\end{array}$ & $\begin{array}{l}\text { Group } 2 \\
\text { saline }\end{array}$ & $\begin{array}{c}\text { Group } 3 \\
\text { pre-propranolol }\end{array}$ & $\begin{array}{c}\text { Group } 4 \\
\text { post-propranolol }\end{array}$ & $p$-value ${ }^{\S}$ \\
\hline $\begin{array}{l}\text { Serum TNF-a } \\
{[\mathrm{pg} / \mathrm{mL}]}\end{array}$ & $\begin{array}{c}70.8 \pm 6.8 \\
71.8(58-77)\end{array}$ & $\begin{array}{c}193 \pm 276^{*} \\
82(75-757)\end{array}$ & $\begin{array}{c}76.7 \pm 1.9 \\
76.2(75-81)\end{array}$ & $\begin{array}{c}100.5 \pm 3.4 \\
99(97-106)\end{array}$ & 0.030 \\
\hline Serum PAI-1 [AU/mL] & $\begin{array}{c}14.5 \pm 1.6 \\
14.1(13-18)\end{array}$ & $\begin{array}{l}18.9 \pm 2.3^{*} \\
18(16-23)\end{array}$ & $\begin{array}{c}19.8 \pm 3.2 \\
19.2(16-26)\end{array}$ & $\begin{array}{c}15 \pm 2.5^{* * *} \\
15.8(10-18)\end{array}$ & 0.021 \\
\hline $\begin{array}{l}\text { Serum VEGF } \\
{[\mathrm{ng} / \mathrm{L}]}\end{array}$ & $\begin{array}{c}631 \pm 56.9 \\
612(564-707)\end{array}$ & $\begin{array}{c}652 \pm 212 \\
697(290-920)\end{array}$ & $\begin{array}{c}742 \pm 114 \\
758.9(568-884)\end{array}$ & $\begin{array}{c}865 \pm 336 \\
783.7(401-1376)\end{array}$ & 0.147 \\
\hline $\begin{array}{l}\text { Serum VEGFR-1 } \\
{[\mathrm{ng} / \mathrm{mL}]}\end{array}$ & $\begin{array}{c}15.7 \pm 2.1 \\
16.4(11.7-17.8)\end{array}$ & $\begin{array}{c}17.9 \pm 1.6 \\
18.2(15.1-19.4)\end{array}$ & $\begin{array}{c}14.4 \pm 3.0^{* *} \\
13.7(11.6-19.1)\end{array}$ & $\begin{array}{c}13.9 \pm 3.0^{* * *} \\
14.1(9.8-17.3)\end{array}$ & 0.053 \\
\hline
\end{tabular}

PAI-1 - plasminogen activator inhibitor-1; TNF-a - tumor necrosis factor alpha; VEGF - vascular endothelial growth factor; VEGFR-1 - vascular endothelial growth factor receptor-1; ${ }^{\S}$ the Kruskal-Wallis test between 4 groups; ${ }^{*} p<0.01$ between sham and sepsis; ${ }^{* *} p<0.01$ between sepsis and pre-propranolol; ${ }_{* * *} p<0.01$ between sepsis and post-propranolol; the values are expressed as mean \pm standard deviation (SD) and as median (min-max); values in bold are statistically significant.

Table 2. Immunocytochemical HSCORE staining among the groups

\begin{tabular}{|l|c|c|c|c|}
\hline \multicolumn{1}{|c|}{$\begin{array}{c}\text { Immunocytochemical } \\
\text { parameters }\end{array}$} & $\begin{array}{c}\text { Group 1 } \\
\text { sham }\end{array}$ & $\begin{array}{c}\text { Group 2 } \\
\text { saline }\end{array}$ & $\begin{array}{c}\text { Group 3 } \\
\text { pre-propranolol }\end{array}$ & $\begin{array}{c}\text { Group 4 } \\
\text { post-propranolol }\end{array}$ \\
\hline $\begin{array}{l}\text { TNF-a score median } \\
\text { (min-max) }\end{array}$ & 22 & $130^{*}$ & $\begin{array}{c}205^{* *} \\
(180-245)\end{array}$ & $(112-261)$ \\
\hline $\begin{array}{l}\text { IL-6 score median } \\
\text { (min-max) }\end{array}$ & $(2-39)$ & $(119-192)$ & 218 & 218 \\
\hline
\end{tabular}

IL-6 - interleukin-6; HSCORE - histological score; TNF-a - tumor necrosis factor alpha; ${ }^{\S}$ the Kruskal-Wallis test between 4 groups; ${ }^{*} \mathrm{p}<0.05$ between sham and sepsis; ${ }^{* *} \mathrm{p}<0.05$ between sepsis and pre-propranolol; values in bold are statistically significant. 


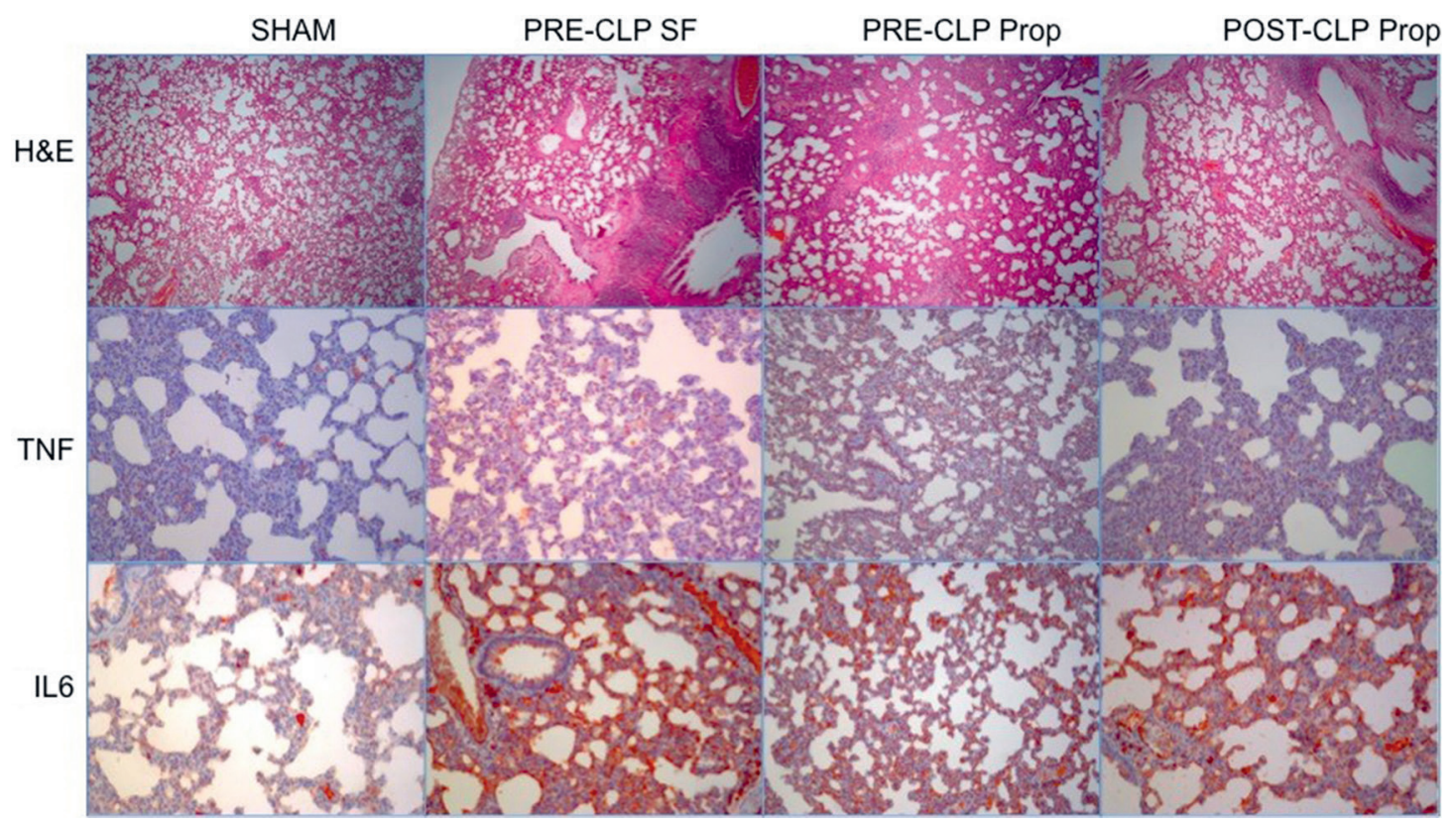

Fig. 2. Immunohistochemical staining of IL-6, TNF-a, and H\&E sections of the lung tissue from each group

SHAM - sham group; PRE-CLP SF - saline group; PRE-CLP Prop - pre-propranolol group; POST-CLP Prop - post-propranolol group; CLP - cecal ligation and puncture; H\&E - hematoxylin and eosin; IL-6 - interleukin-6; TNF-a - tumor necrosis factor alpha; Prop - propranolol; SF - saline.
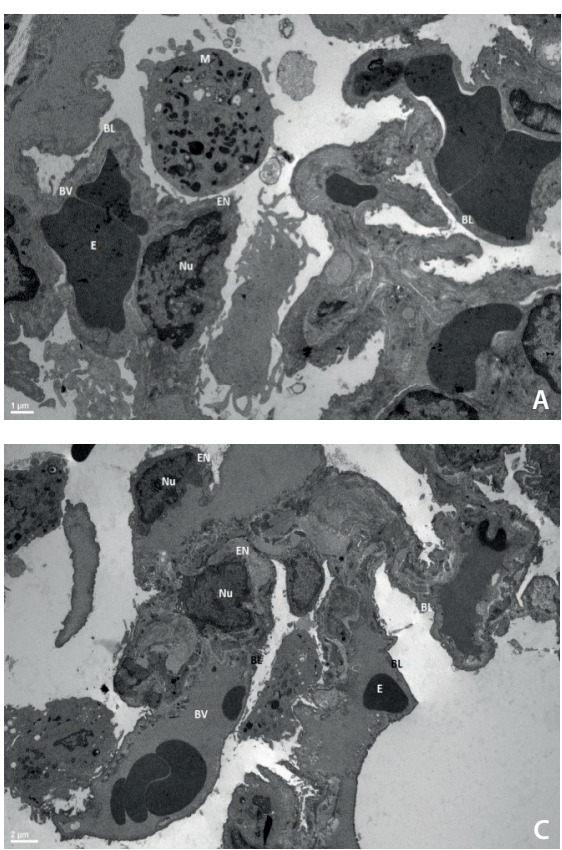
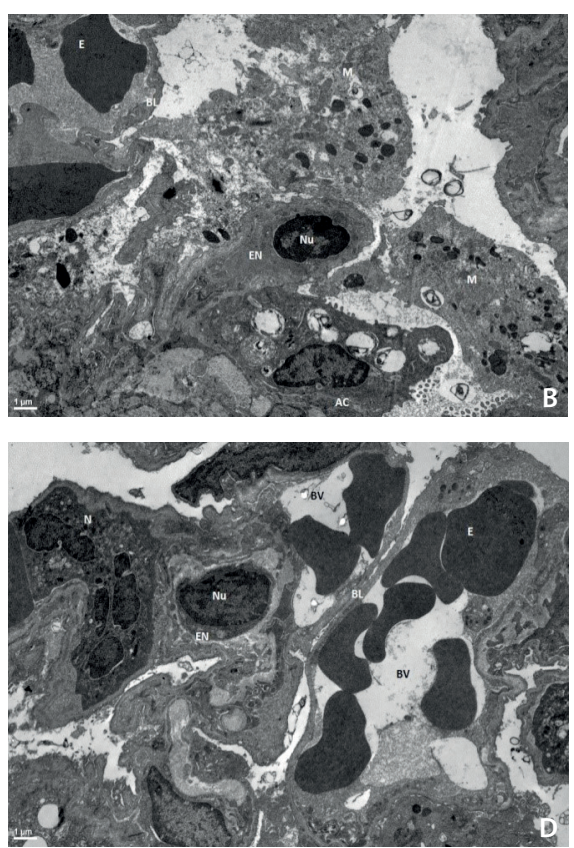

Fig. 3. Electron microscopic examination of the lung tissue of the animals

A - electron microscopic view from the sham group. The capillary endothelial cells preserved their normal structure in the nuclei and cytoplasmic organelles. Bar: 1 um; B - electron microscopic view from the septic control group. There was an increase in the amount of heterochromatin in the nucleus of the endothelial cells. There were phagocytic bodies in the cytoplasm of the macrophages. Bar: $1 \mu \mathrm{m}$ $\mathrm{C}$ - electron microscopic view from the prepropranol group. The capillary endothelial cells and basal lamina preserved their ultrastructure in many areas. However, in some areas there was an increase in the amount of heterochromatin in the nuclei of the endothelial cells. Bar: $2 \mu \mathrm{m}$ $D$ - electron microscopic view from the postpropranol group. The capillary endothelial cells and basal lamina preserved their normal structure in many areas. Bar: $1 \mu \mathrm{m}$.

AC - type 2 alveolar cell; BL - basal lamina of capillary endothelial cell; BV - blood vessel; E - erythrocyte; EN - endothelial cells; $\mathrm{M}$ - macrophage; $\mathrm{N}$ - neutrophil; $\mathrm{Nu}$ - nuclei. exerts a protective effect on systemic inflammation, coagulation and survival when applied before the septic insult. To the best of our knowledge, we showed for the first time that the underlying mechanism of the action of propranolol in sepsis may be the improvement of endothelial function as well.

The idea of administering $\beta$-blockers in sepsis is not novel. In the first study, which was performed in the late 1960s, Berk et al. documented a favorable survival rate with no pathological changes of pulmonary congestion in septic dogs with the use of propranolol. ${ }^{13}$ Since then, there has been growing interest in the use of $\beta$-blockers in sepsis, with a number of mostly experimental studies being published; however, the mortality data is contradictory. ${ }^{10,12,14-16}$ This is possibly due to the inconsistency in animal sepsis models, the receptor specificity of the selected agents, the dosage, and the timing of treatment. ${ }^{17}$ In a previous report, Ackland et al. showed that metoprolol and atenolol markedly improved survival and reduced inflammation when initiated $48 \mathrm{~h}$ before sepsis. However, the favorable survival effect disappeared in this study when the $\beta$-blockage was implemented $6 \mathrm{~h}$ after the induction of sepsis. ${ }^{14}$ In another report, Wilson et al. verified a similar effect with propranolol when administered 
30 min prior to and $24 \mathrm{~h}$ after sepsis. ${ }^{12}$ The results of the present study are in accordance with the previous experimental reports, which showed enhanced survival with the prior administration of $\beta$-blockers in sepsis. This endpoint is also supported by 2 clinical studies. In the first report, Macchia et al. studied the database of 9,465 patients who were hospitalized in critical care units for sepsis, and despite a higher risk profile, the patients previously prescribed $\beta$-blockers had a lower mortality rate after 28 days (odds ratio (OR): 0.78 ; 95\% confidence interval (CI): 0.66-0.93; $\mathrm{p}=0.005) .{ }^{18}$ The only randomized clinical trial which was performed with esmolol also confirmed these results, although its findings have been criticized, particularly due to the unexplicably high mortality in the control group. ${ }^{19}$ Currently, clinical trials are ongoing to elucidate this inconsistent clinical data.

The physiological rationale behind the clinical application of $\beta$-blockers in sepsis was firstly based on the cardiovascular modulation effect. ${ }^{13,20}$ Later, various mechanisms of action, including inflammatory, metabolic and coagulation effects, have been proposed. ${ }^{3}$ Another notably logical reason for the use of $\beta$-blockers in sepsis is catecholamine-derived endothelial dysfunction. ${ }^{21}$ A growing body of evidence showed that $\beta$-blockers counteract the adrenergic storm in sepsis by modulating cytokine profile production and modulate the coagulation system. ${ }^{3-5,22}$ Specifically, propranolol was reported to suppress the catecholamine-driven increase in natural killer cells and result in a marked decrease in the production of chemokine (C-C motif) ligand 3 (CCL3), which is a macrophage-derived inflammatory protein that facilitates the clearance of the pathogen. ${ }^{23,24}$ Herein, we report that $\beta$-blocker treatment, either administered prior to or after the induction of sepsis, significantly suppressed serum levels of VEGFR-1, which plays a key role in activating monocytes/macrophages. Besides, our results demonstrate that propranolol treatment, when administered after septic insult, alleviates the PAI-1 levels. Plasminogen activator inhibitor-1 is a well-known crucial glycoprotein of hemostasis synthesized by the endothelium and the liver, and is incrementally released during inflammation. Further evaluation of the potential effect of $\beta$-blockers on inflammation and the coagulation system might help to find a potential pharmacological strategy for the treatment of sepsis.

Interestingly, a huge amount of previous evidence has yielded potential favorable effects of $\beta$-blockers on the endothelium in non-septic conditions. ${ }^{25-28}$ In a previous report, Jawa et al. showed that $\beta$-blockers had a beneficial effect on endothelial function in patients with diabetes and hypertension. ${ }^{25}$ Also, Joseph and Levine reported that $\beta$-blockers induced anti-hyperalgesia via the endothelial cells, which has been implicated in diverse pain syndromes, such as migraines. ${ }^{29}$ Later, Perros et al. indicated that $\beta$-blockage improves endothelial function in pulmonary arterial hypertension. ${ }^{30}$ Additionally, it is an effective treatment modality in infantile hemangioma, whose potential mechanism of action has been suggested to be a combination effect on the endothelium. ${ }^{31}$ Recently, a meta-analysis which included 16 clinical studies with 1,273 patients with cardiovascular disease clearly confirmed a potential ameliorating effect of $\beta$-blockers on endothelial dysfunction. ${ }^{32}$

On the other hand, data which focuses on the effect of $\beta$-blockers on the endothelium in sepsis is extremely limited. In a recent experimental study, Jacquet-Lagrèze et al. investigated the effect of esmolol on gut and sublingual microcirculation after the septic insult, and they reported that esmolol allowed a better maintenance of gut microcirculation despite a reduction in stroke index scores. ${ }^{33}$ In the first pilot clinical study to specifically investigate the microcirculatory effects in septic shock patients with side stream dark field imaging, Morelli et al. demonstrated the preserving influence of esmolol on the microvascular flow. ${ }^{34}$ However, various $\beta$-blockers may have different effects due to fitful receptor specificity, and to the best of our knowledge, no previous report has focused on the effect of propranolol on endothelial dysfunction. Our results are principally in agreement with previous reports, which demonstrated that propranolol treatment may alleviate endothelial dysfunction.

Several limitations of this study must be taken into account. First of all, one can propose that prior administration of propranolol may not be feasible due to the inconsistency of developing sepsis in clinical practice. However, this may be essential in high-risk groups, such as surgery or burn patients, in whom sepsis development risk and its related mortality are expected to be high. Secondly, we did not perform hemodynamic monitoring. Although propranolol treatment is expected to reduce the heart rate or cardiac output, we selected a dosage which is $30 \%$ less than that applied in a previous study, which showed no hemodynamic compromise. ${ }^{16}$ Moreover, we had formerly performed a pilot study to test the potential fatal effect of the propranolol administration itself and we did not observe any mortality. Owing to the fact that we succeeded in showing the improved endothelial function and survival, we think that the lack of hemodynamic monitoring did not significantly affect our results. However, further studies with higher doses may better show the survival advantage in post-propranolol groups. Although we evaluated endothelial function in terms of barrier function, inflammation and hemostasis, we could not evaluate glycocalyx due to the collapse of the tissue during processing.

\section{Conclusions}

This study documented a significant survival advantage for septic rats who were given a non-selective $\beta$-blocker prior to the septic insult. This outcome benefit may be due to the ameliorated endothelial dysfunction or to previously described effects. Further experimental and clinical studies, which may lead to a full understanding of the 
underlying mechanisms by which propranolol exerts its effects on sepsis, should not only allow for new treatment options, but may also improve survival.

\section{References}

1. Gohil SK, Cao C, Phelan M, et al. Impact of policies on the rise in sepsis incidence, 2000-2010. Clin Infect Dis. 2016;62(6):695-703.

2. Ince C, Mayeux PR, Nguyen T, et al; ADQI XIV Workgroup. The endothelium in sepsis. Shock. 2016;45(3):259-270.

3. de Montmollin E, Aboab J, Mansart A, Annane D. Bench-to-bedside review: Beta-adrenergic modulation in sepsis. Crit Care. 2009; 13(5):230.

4. Deng J, Muthu K, Gamelli R, Shankar R, Jones SB. Adrenergic modulation of splenic macrophage cytokine release in polymicrobial sepsis. Am J Physiol Cell Physiol. 2004;287(3):C730-736.

5. Muthu K, Deng J, Romano F, et al. Thermal injury and sepsis modulates beta-adrenergic receptors and CAMP responses in monocyte-committed bone marrow cells. J Neuroimmunol. 2005;165(1-2): 129-138.

6. Cohen MJ, Shankar R, Stevenson J, Fernandez R, Gamelli RL, Jones $\mathrm{SB}$. Bone marrow norepinephrine mediates development of functionally different macrophages after thermal injury and sepsis. Ann Surg. 2004;240(1):132-141.

7. Heilbrunn SM, Shah P, Bristow MR, Valantine HA, Ginsburg R, Fowler $M B$. Increased beta-receptor density and improved hemodynamic response to catecholamine stimulation during long-term metoprolol therapy in heart failure from dilated cardiomyopathy. Circulation. 1989;79(3):483-490.

8. Prass K, Meisel C, Hoeflich C, et al. Stroke induced immunodeficiency promotes spontaneous bacterial infections and is mediated by sympathetic activation reversal by poststroke T helper cell type 1-like immunostimulation. J Exp Med. 2003;198(5):725-736.

9. Boomer JS, To K, Chang KC, et al. Immunosuppression in patients who die of sepsis and multiple organ failure. JAMA. 2011;306(23):25942605.

10. Mori K, Morisaki H, Yajima S, et al. Beta-1 blocker improves survival of septic rats through preservation of gut barrier function. Intensive Care Med. 2011;37(11):1849-1856.

11. Rittirsch D, Huber-Lang MS, Flierl MA, Ward PA. Immunodesign of experimental sepsis by cecal ligation and puncture. Nat Protoc. 2009; 4(1):31-36.

12. Wilson J, Higgins $D$, Hutting $H$, et al. Early propranolol treatment induces lung hemeoxygenase-1, attenuates metabolic dysfunction, and improves survival following experimental sepsis. Crit Care. 2013;17(5):R195.

13. Berk JL, Hagen JF, Beyer WH, Gerber MJ, Dochat GR. The treatment of endotoxin shock by beta adrenergic blockade. Ann Surg. 1969;169 (1):74-81.

14. Ackland GL, Yao ST, Rudiger A, et al. Cardioprotection, attenuated systemic inflammation, and survival benefit of 1-adrenoceptor blockade in severe sepsis in rats. Crit Care Med. 2010;38(2):388-394.

15. Ibrahim-Zada I, Rhee P, Gomez CT, Weller J, Friese RS. Inhibition of sepsis-induced inflammatory response by beta1-adrenergic antagonists. J Trauma Acute Care Surg. 2014;76(2):320-327.
16. Sanfilippo F, Santonocito C, Morelli A, Foex P. Beta-blocker use in severe sepsis and septic shock: A systematic review. Curr Med Res Opin. 2015;31(10):1817-1825.

17. Rudiger A. Beta-block the septic heart.CritCareMed.2010;38(Suppl 10): 608-612.

18. Macchia A, Romero M, Comignani PD, et al. Previous prescription of $\beta$-blockers is associated with reduced mortality among patients hospitalized in intensive care units for sepsis. Crit Care Med. 2012;40 (10):2768-2772.

19. Morelli A, Ertmer C, Westphal M, et al. Effect of heart rate control with esmolol on hemodynamic and clinical outcomes in patients with septic shock: A randomized clinical trial. JAMA. 2013;310(16): 1683-1691.

20. Berk JL, Hagen JF, Maly G, Koo R. The treatment of shock with beta adrenergic blockade. Arch Surg. 1972;104(1):46-51.

21. Johansson PI, Haase N, Perner A, Ostrowski SR. Association between sympathoadrenal activation, fibrinolysis, and endothelial damage in septic patients: A prospective study. J Crit Care. 2014;29(3):327-333.

22. Hamzaoui O, Teboul JL. The role of beta-blockers in septic patients. Minerva Anestesiol. 2015;81(3):312-319.

23. Oberbeck R. Catecholamines: Physiological immunomodulators during health and illness. Curr Med Chem. 2006;13(17):1979-1989.

24. Takahashi H, Kobayashi M, Tsuda Y, Herndon DN, Suzuki F. Contribution of the sympathetic nervous system on the burn-associated impairment of CCL3 production. Cytokine. 2005;29(5):208-214.

25. Jawa A, Nachimuthu S, Pendergrass M, Asnani S, Fonseca V. Betablockers have a beneficial effect upon endothelial function and microalbuminuria in African-American subjects with diabetes and hypertension. J Diabetes Complications. 2008;22(5):303-308.

26. Lin ZP, Dong M, Liu J. Bisoprolol improved endothelial function and myocardium survival of hypertension with stable angina: A randomized double-blinded trial. Eur Rev Med Pharmacol Sci. 2013;17(6): 794-801.

27. Pasini AF, Garbin U, Stranieri $C$, et al. Nebivolol treatment reduces serum levels of asymmetric dimethylarginine and improves endothelial dysfunction in essential hypertensive patients. Am J Hypertens. 2008;21(11):1251-1257.

28. Nerla R, Di Franco A, Milo M, et al. Differential effects of heart rate reduction by atenolol or ivabradine on peripheral endothelial function in type 2 diabetic patients. Heart. 2012;98(24):1812-1816.

29. Joseph EK, Levine JD. Role of endothelial cells in antihyperalgesia induced by a triptan and $\beta$-blocker. Neuroscience. 2013;232:83-89.

30. Perros F, Ranchoux B, Izikki M, et al. Nebivolol for improving endothelial dysfunction, pulmonary vascular remodeling, and right heart function in pulmonary hypertension. J Am Coll Cardiol. 2015;65(7): 668-680.

31. Ji Y, Chen S, Xu C, Li L, Xiang B. The use of propranolol in the treatment of infantile hemangiomas: An update on potential mechanisms of action. Br J Dermatol. 2015;172(1):24-32.

32. Peller M, Ozierański K, Balsam P, Grabowski M, Filipiak KJ, Opolski G. Influence of beta-blockers on endothelial function: A meta-analysis of randomized controlled trials. Cardiol J. 2015;22(6):708-716.

33. Jacquet-Lagrèze $M$, Allaouchiche $B$, Restagno $D$, et al. Gut and sublingual microvascular effect of esmolol during septic shock in a porcine model. Crit Care. 2015;19:241.

34. Morelli A, Donati A, Ertmer C, et al. Microvascular effects of heart rate control with esmolol in patients with septic shock: A pilot study. Crit Care Med. 2013;41(9):2162-2168. 